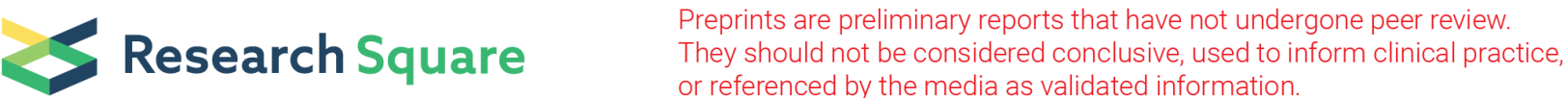

\section{In vitro protective effects of Lactobacillus plantarum Lac16 on Clostridium perfringens infection-associated intestinal injury in IPEC-J2 cells}

Yuanhao Zhou ( $\square$ zyh17767072477@163.com )

Zhejiang University https://orcid.org/0000-0003-4354-9987

\section{Baikui Wang}

Zhejiang University

Qi Wang

Zhejiang University

Li Tang

Zhejiang University

\section{Peng Zou}

Zhejiang University

\section{Zihan Zeng}

Zhejiang University

\section{Huihua Zhang}

Foshan University

\section{Li Gong}

Zhejiang University

Weifen Li

Zhejiang University

\section{Research}

Keywords: Lactobacillus plantarum, Clostridium perfringens, intestinal injury, intestinal barrier integrity, inflammation

Posted Date: April 30th, 2021

DOI: https://doi.org/10.21203/rs.3.rs-463175/v1

License: (9) (i) This work is licensed under a Creative Commons Attribution 4.0 International License. Read Full License 


\section{Abstract}

Background: Clostridium perfringens causes intestinal injury through overgrowth and secretion of multiple toxins, leading to diarrhea and necrotic enteritis in animals, such as pigs. Lactobacillus plantarum $(L$. plantarum) Lac16 has been reported to protect broilers against $C$. perfringens infection. This study aimed at investigating the protective effects of Lactobacillus plantarum Lac16 on C. perfringens infection-associated intestinal injury in intestinal porcine epithelial cell line (IPEC-J2).

Results: The results showed that $L$. plantarum Lac16 significantly inhibit the growth and biofilm formation of $C$. perfringens $(P<0.001)$. In the co-culture system, L. plantarum Lac16 significantly suppressed colony forming units (CFU) of $C$. perfringens $(P<0.05)$, which was accompanied by a decrease in pH levels $(P<0.01)$. Moreover, $L$. plantarum Lac16 significantly elevated the mRNA expression levels of host defense peptides (HDPs) in IPEC-J2 cells $(P<0.05)$, decreased $C$. perfringens-induced cellular cytotoxicity $(P<0.01)$ and adhesion to cells $(P<0.05)$. At the same time, $L$. plantarum Lac16 significantly attenuated $C$. perfringensinduced damage to intestinal barrier integrity and the decrease in claudin-1 $(P<0.01)$ as well as zona occludens 1 (ZO-1) expressions. Preincubation with L. plantarum Lac16 significantly suppressed mRNA expression levels of pattern recognition receptors (PRRs) (Toll-like receptor (TLR) 1, TLR2, nucleotide-binding oligomerization domain (NOD) 1) in $C$. perfringens-challenged IPEC-J2 cells $(P<0.01)$. C. perfringens significantly elevated the phosphorylation of p38 mitogen-activated protein kinase (MAPK), JNK, and p65 nuclear factor-KB $(\mathrm{NF}-\mathrm{KB})(P<0.05)$ while $L$. plantarum Lac16 pre-incubation effectively inhibited phosphorylation of p65 $(P<0.001)$. Furthermore, $L$. plantarum Lac16 significantly suppressed $C$. perfringens induced gene expressions of proinflammatory cytokines (interleukin (IL)-1 $\beta, I L-6, I L-8$, tumor necrosis factor-a $(T N F-a))(P<0.05)$.

Conclusions: Collectively, probiotic $L$. plantarum Lac16 exerts protective effects against $C$. perfringens infection-associated intestinal injury in IPEC-J2 cells.

\section{Background}

C. perfringens is a Gram-positive, spore-forming, anaerobic, rod-shaped bacterium [1,2]. C. perfringens can be isolated from the natural environment (e.g., soil), and from human as well as animal intestines as a component of the normal microbial community[3]. However, under certain conditions, such as $C$. perfringens overgrowth or disruption of the intestinal microbiota, $C$. perfringens causes various intestinal diseases $[4,5]$. C. perfringens strains have been reported to secrete more than twenty toxins or enzymes, which are principal virulence factors [4]. Based on the secretion of four major toxins ( $a, \beta, \varepsilon$, and $\iota), C$. perfringens can be grouped into five different toxin types (types A to E) [6]. Among them, $C$. perfringens type A is very common in the intestines of warmblooded animals, and under the above mentioned conditions, it causes intestinal diseases in domestic animals, such as pigs, chicken, and sheep [3]. Symptoms of its infection in piglets include severe diarrhoea, accompanied by necrotic mucosa and intestinal villi atrophy $[7,8]$. Currently, C. perfringens infections has become an important problem hindering the development of the pig industry $[9,10]$.

Probiotics are defined as "live microorganisms that, when administered in adequate amounts, confer a health benefit on the host" [11]. In animal husbandry, beneficial effects of probiotics are mainly reflected in nutrition and immunity [12]. They promote animal health by regulating immune functions and maintaining dynamic 
balance of intestinal microbiota $[13,14]$. Lactobacillus spp. have been shown to exert protective effects against C. perfringens infection in vivo and in vitro. Guo et al. [15] reported that L. acidophilus and L. fermentum inhibited the growth and a-toxin production capacity of $C$. perfringens in vitro. At the same time, another study showed that $L$. fermentum also inhibited $\beta 2$-toxin secretion [16]. Furthermore, members of Lactobacillus spp., such as L. fermentumc, L. salivarius, L. plantarum, and L. acidophilus inhibit $C$. perfringens infection associated necrotic enteritis by improving intestinal morphology and barrier integrity, reducing lesions, ameliorating inflammation, as well as by modulating intestinal microbiota [17-20].

In our previous study, we found that L. plantarum Lac16 effectively protected broilers from $C$. perfringens infection [21]. However, it has not been established whether L. plantarum Lac16 can protect pig intestines in cases of $C$. perfringens infection. The porcine jejunal epithelial cell line, IPEC-J2, has exhibited a high specificity in pig studies and is a suitable model for investigating the interactions between bacteria and intestinal epitheliums in vitro $[22,23]$. Thus, this study aimed at investigating the protective effects of L. plantarum Lac16 on $C$. perfringens infection-associated intestinal injury in IPEC-J2 cells in vitro.

\section{Methods}

\section{Bacterial strains and culture conditions.}

L. plantarum Lac16 (CCTCC, No. M2016259) was isolated in our laboratory and preserved at the China Center for Type Culture Collection. L. plantarum Lac16 was cultured in Mann-Rogosa-Sharpe (MRS) medium and incubated at $37^{\circ} \mathrm{C}$ for $18 \mathrm{~h}$. C. perfringens type A (ATCC 13124) was cultured in Reinforced clostridium medium (RCM; Hopebio, Qingdao, China) and incubated at $37^{\circ} \mathrm{C}$ in anaerobic conditions for $18 \mathrm{~h}$.

To determine bacterial concentrations, we centrifuged the overnight-incubated bacterial cultures at $5000 \mathrm{rpm}$ for $5 \mathrm{~min}$. After being washed three times using sterile phosphate-buffered saline (PBS, $\mathrm{pH}=7.2)$, bacteria were resuspended in PBS and their concentrations determined using a standard curve. Then, they were diluted to a certain concentration and stored at $4{ }^{\circ} \mathrm{C}$.

\section{Agar-diffusion method for detecting bacteriostasis of L. plantarum Lac 16 in a fermentation supernatant.}

Agar-diffusion was performed as previously described by Wang et al. [24] with some modifications. Briefly, L. plantarum broth was centrifuged at $5000 \mathrm{rpm}$ for $10 \mathrm{~min}$ to obtain the supernatant. The supernatant was filtered through a $0.22 \mu \mathrm{m}$ membrane to remove suspended bacteria and stored at $4{ }^{\circ} \mathrm{C}$. About $0.2 \%(\mathrm{v} / \mathrm{v})$ of the overnight culture of $C$. perfringens was added to tryptose sulfite cycloserine (TSC; Hopebio, Qingdao, China) agar which cooled down to about $50{ }^{\circ} \mathrm{C}$. Then, the medium was well mixed and poured into plastic plates which placed oxford cups in advance. The oxford cups were removed after the medium had solidified. Then, $100 \mu \mathrm{L}$ of L. plantarum Lac16 fermentation supernatants were injected into each well after which plates were placed in anaerobic gas generating packs (Hopebio, Qingdao, China) for $12 \mathrm{~h}$. This bacteriostatic experiment was performed in triplicates.

\section{Biofilm assays.}

Biofilm assays were performed as previously described by Jiang et al. [25] with some modifications. $L$. plantarum and C. perfringens were cultured in modified RCM medium (glucose content was increased to $20 \mathrm{~g} / \mathrm{L}$ 
on the original basis) and incubated at $37^{\circ} \mathrm{C}$ for $18 \mathrm{~h}$, respectively. Then, the concentration of the $C$.

perfringens culture was adjusted to $10^{7} \mathrm{CFU} / \mathrm{mL}$ using the modified RCM medium, after which the supernatant of L. plantarum was collected as described above.

Experimental groups were treated as: i. Sterile modified RCM medium $(200 \mu \mathrm{L})$ were inoculated into 96 -well culture plates and designed as the control group; ii. Resuspended C. perfringens $(100 \mu \mathrm{L})$ or $100 \mu \mathrm{L}$ of $L$. plantarum supernatant were added to $100 \mu \mathrm{L}$ of sterile modified RCM medium, and designed as the $\mathrm{CP}$ or Lac16 fermentation supernatant group; iii. L. plantarum fermentation supernatant $(100 \mu \mathrm{L})$ and $100 \mu \mathrm{L}$ of resuspended $C$. perfringens were inoculated and designed as the experimental treatment group, which was labeled Lac16 fermentation supernatant + Cp group. The 96-well culture plate was incubated in an anaerobic environment at $37{ }^{\circ} \mathrm{C}$ for $12 \mathrm{~h}$ after which the bacterial proliferation index was read at $\mathrm{OD}_{600}$ using SpectraMax M5 (Molecular Devices, USA). Then, bacterial cultures were removed with caution, wells were gently washed thrice using PBS and incubated with $100 \mu \mathrm{L}$ of $1 \%$ crystal violet for $30 \mathrm{~min}$. Crystal violet in the wells was removed and wells were gently washed thrice using PBS. Then, $100 \mu \mathrm{L}$ of $95 \%$ alcohol was added into the wells to dissolve excess crystal violet and $\mathrm{OD}_{590}$ in each well measured. The higher the optical density, the more biofilm formation. Experiments were done in triplicates.

\section{Co-culture experiment and $\mathrm{pH}$ determination of cultures.}

Bacterial co-culture experiments were done as previously described by Guo et al. [15] with some modifications. L. plantarum and C. perfringens were adjusted to $10^{7} \mathrm{CFU} / \mathrm{mL}$ using the modified RCM medium. Ten milliliter of the modified RCM medium were used as the blank control. At the same time, L. plantarum or $C$. perfringens suspensions $(100 \mu \mathrm{L})$ were inoculated in $9.9 \mathrm{~mL}$ of modified RCM medium as single bacterial strain groups, respectively. Regarding the co-culture system, $100 \mu \mathrm{L}$ of $L$. plantarum and $C$. perfringens were both inoculated in $9.8 \mathrm{~mL}$ of modified RCM medium. The above cultures were incubated at $37^{\circ} \mathrm{C}$ for $12 \mathrm{~h}$, their pH values were determined, after which they were serially diluted, cultured on TSC agar and incubated at $37^{\circ} \mathrm{C}$ for $12 \mathrm{~h}$ to quantitate $C$. perfringens populations. These experiments were done in triplicates.

\section{Cell cultures.}

IPEC-J2 cells were cultured in Dulbecco's modified Eagle's F12 ham medium (DMEM/F12; Gibco, MA, USA) supplemented with $10 \%$ (v/v) fetal bovine serum (FBS; Gibco, MA, USA), $100 \mu \mathrm{g} / \mathrm{mL}$ streptomycin and 100 $\mathrm{U} / \mathrm{mL}$ penicillin (Sigma-Aldrich, MO, USA). Incubation was done at $37^{\circ} \mathrm{C}$ in an atmosphere of $90 \%$ humidity and $5 \% \mathrm{CO}_{2}$. When cell confluence reached $80 \%$, cells were digested using $0.25 \%$ trypsin-EDTA solution (Gibco, MA, USA) and seeded in cell culture plates.

\section{Determination of expression levels of HDPs by Real-Time PCR.}

IPEC-J2 cells were seeded in 12-well cell culture plates (Corning Life Science, MA, USA) at a density of $5 \times 10^{5}$ cells/well. L. plantarum cultures were centrifuged and resuspended in DMEM/F12 supplemented with $10 \%$ FBS and stored at $4{ }^{\circ} \mathrm{C}$. When IPEC-J2 cells reached $80 \%$ confluence, they were co-incubated in cell culture media containing different concentrations of $L$. plantarum Lac16 $\left(10^{6}, 10^{7}\right.$, and $\left.10^{8} \mathrm{CFU} / \mathrm{mL}\right)$ for $6 \mathrm{~h}$. After being washed three times using PBS, IPEC-J2 cells were lysed by RNAiso Plus (Takara, Dalian, China) to extract RNA. 
Expression levels of porcine $\beta$-defensin $(p B D 1, p B D 2, p B D 3)$ and porcine epididymis protein 2 splicing variant $C$ ( $p E P 2 C)$ were then determined by real-time PCR. All experiments were performed in triplicates.

\section{Cytotoxicity Assay.}

IPEC-J2 cells were seeded in 12-well culture plates at a density of $5 \times 10^{5}$ cells/well. When cells reached $80 \%$ confluence, they were incubated with or without L. plantarum $\left(10^{7} \mathrm{CFU} / \mathrm{mL}\right)$ for $6 \mathrm{~h}$, respectively. After being washed three times using PBS, cells were infected with $C$. perfringens $\left(10^{6} \mathrm{CFU} /\right.$ well) under anaerobic conditions for $1 \mathrm{~h}$ or $3 \mathrm{~h}$, respectively. Then, cell suspensions were collected and centrifuged at $10000 \mathrm{rpm} / \mathrm{min}$ for $5 \mathrm{~min}$ to remove cell debris and bacteria. The release of lactate dehydrogenase (LDH) from damaged cells was measured using the LDH kit (Nanjing Jiancheng Biological Product, Nanjing, China), according to the manufacturer's instructions. Experiments were performed in triplicates.

\section{Perfringens adhesion assay.}

Bacterial adhesion assay was performed as previously described by Jiang et al. [25] with some modifications. Briefly, IPEC-J2 cells were seeded in 12-well cell culture plates at a density of $5 \times 10^{5}$ cells/well. At $80 \%$ confluence, cells were pre-incubated with L. plantarum $\left(10^{7} \mathrm{CFU} / \mathrm{mL}\right)$ for $6 \mathrm{~h}$, after which C. perfringens were added into the wells $\left(10^{6} \mathrm{CFU} / \mathrm{mL}\right)$ and incubated for $1 \mathrm{~h}$ under anaerobic conditions. Cells treated with $C$. perfringens only were used as the controls. Then, cells were washed three times using sterile PBS to remove non-adherent $C$. perfringens. Two hundred microliters of $0.25 \%$ trypsin-EDTA solution was added to the wells and digested for $15 \mathrm{~min}$, then, $800 \mu \mathrm{L}$ sterile PBS was added to each well and completely mixed. Liquids containing bacteria were serially diluted and incubated in TSC agar for $12 \mathrm{~h}$ to quantitate $C$. perfringens populations. Each assay was performed in triplicate.

At the same time, we used fluorescein isothiocyanate (FITC; Solarbio, Beijing, China) labeling method to observe the adhesion effect of $C$. perfringens. Briefly, the concentration of $C$. perfringens culture, after centrifuged, was adjusted to $10^{7} \mathrm{CFU} / \mathrm{mL}$ with diluted FITC-solution (200 $\left.\mu \mathrm{g} / \mathrm{mL}\right)$. Avoid light and incubate for $2 \mathrm{~h}$ at $37^{\circ} \mathrm{C}$. Then the bacteria were washed with sterile PBS for three times and storaged at $4{ }^{\circ} \mathrm{C}$. After incubation with L. plantarum Lac16 for $6 \mathrm{~h}$, the cells were washed three times with sterile PBS and co-incubated with $C$. perfringens $\left(10^{6} \mathrm{CFU} / \mathrm{mL}\right)$, which was labeled with FITC, for $1 \mathrm{~h}$ under anaerobic conditions and away from light. Then the cells were washed three times with sterile PBS and examined under a fluorescence microscope (Nikon, Japan). All experiments were performed in triplicate.

\section{Cell permeability to fluorescein sodium.}

Cell permeability to fluorescein sodium was assessed as previously described by Nie et al. [26] with some modifications. Briefly, IPEC-J2 cells were seeded in 12-well transwell inserts (Corning Life Science, MA, USA), with pore sizes of $0.4 \mathrm{~mm}$ and membrane areas of $1.12 \mathrm{~cm}^{2}$, at a concentration of $1 \times 10^{5} \mathrm{cells} / \mathrm{mL}$. Since IPEC-J2 cells can develop tight junctions and differentiate into tight monolayers after 9 days of culture on transwell filters [22], we renewed the culture medium in both apical and basolateral sides of the filters every 24 $\mathrm{h}$ for 9 days. On the $10^{\text {th }}$ day, the culture medium on the apical side of the filters was removed and IPEC-J2 cells were treated as described in adhesion assay section. Then, $100 \mu \mathrm{g} / \mathrm{mL}$ fluorescein sodium (Sigma-Aldrich, MO, USA), dissolved in PBS, was added to the apical inserts for $1 \mathrm{~h}$, after which $200 \mu \mathrm{L}$ of medium from each 
basolateral side was collected. Fluorescence intensity was determined using a SpectraMax M5 (Molecular Devices, USA) at an excitation wavelength of $495 \mathrm{~nm}$ and an emission wavelength of $525 \mathrm{~nm}$. Then, we calculated apical to basolateral flux of fluorescein sodium using the standard curve. Apparent permeability coefficient $\left(P_{\text {app }}\right)$ was calculated using the formula: $P_{\text {app }}=\Delta Q / \Delta t \times\left(1 / A C_{0}\right)$ [26]. Whereby, $\Delta Q / \Delta t$ is the permeability rate $(\mu \mathrm{g} / \mathrm{s}), A$ is the diffusion area of the monolayer $\left(\mathrm{cm}^{2}\right)$, while $C_{0}$ is the initial concentration $(\mu \mathrm{g} / \mathrm{mL})$ of fluorescein sodium in the transwell apical inserts. All experiments were performed in triplicates.

\section{Immunofluorescence analysis.}

IPEC-J2 cells $\left(5 \times 10^{5}\right.$ cell $\left./ \mathrm{mL}\right)$ were seeded on glass coverslips in a 12-well flat-bottom culture plate for at least 9 days to form tight junctions. On the $10^{\text {th }}$ day, the monolayer reaching polarization was treated with bacteria as described in adhesion assay section. Cells were fixed in 4\% paraformaldehyde for 20 min at room temperature and blocked with 2.5\% bovine serum albumin (BSA; Solarbio, Beijing, China) for $1 \mathrm{~h}$ at room temperature. Cells were incubated with rabbit polyclonal anti-ZO-1 primary antibody (Invitrogen, MA, USA) for $12 \mathrm{~h}$ at $4{ }^{\circ} \mathrm{C}$, after which they were incubated with secondary antibody Alexa fluor 488 goat anti-rabbit (Abcam, Cambridge, UK) for $1 \mathrm{~h}$ at room temperature and away from light. Nuclei were stained with 4',6-Diamidino-2phenylindole dihydrochloride (DAPI; Beyotime, Shanghai, China). Fluorescence images were obtained through laser scanning confocal microscopy (LSM 880 with AiryScan) (Zeiss, Germany). All experiments were performed in triplicates.

\section{Periodic acid-Schiff (PAS) staining.}

The IPEC-J2 cells $\left(5 \times 10^{5}\right.$ cell/mL) were grown in 24-well plates (Corning Life Science, MA, USA) for 9 days and pretreated with bacteria as described in adhesion assay section. Then, cells were washed using PBS and fixed in $70 \%$ ethanol for 10 min at room temperature. Periodic acid-Schiff staining was performed according to the manufacturer's instructions (Beyotime, Shanghai, China). Images were obtained using a light microscope (Leica, Germany). Experiments were performed in triplicate.

\section{Quantitative Real-Time PCR.}

IPEC-J2 cells were pretreated with bacteria as described in adhesion assay section. Then, cells were lysed using RNAiso Plus (Takara, Dalian, China) to extract RNA. Total RNA was reverse transcribed to cDNA using the HiScript II Q Select RT SuperMix (Vazyme, Nanjing, China). The qRT-PCR analysis was performed using StepOne Plus Real-Time PCR system (Applied Biosystems, USA) and the ChamQ Universal SYBR qPCR Master Mix (Vazyme, Nanjing, China). Primer sequences used in this study are shown in Table 1. All samples were run in triplicates. $\beta$-actin was selected as an endogenous control and relative gene expressions were analyzed using the $2^{-\Delta \Delta C t}$ method [27]. Each assay was performed in triplicate.

\section{Table 1. Primers used for quantitative real-time PCR}




\begin{tabular}{|c|c|c|c|}
\hline $\begin{array}{l}\text { Gene } \\
\text { Name }\end{array}$ & Forward sequence $\left(5^{\prime} \rightarrow 3^{\prime}\right)$ & Reverse sequence $\left(5^{\prime} \rightarrow 3^{\prime}\right)$ & $\begin{array}{l}\text { Accession } \\
\text { Number }\end{array}$ \\
\hline$\beta$-actin & CCAGGTCATCACCATCGGCAAC & CAGCACCGTGTTGGCGTAGAG & DQ845171.1 \\
\hline pBD1 & TTCCTCCTCATGGTCCTGTT & AGGTGCCGATCTGTTTCATC & NM_213838.1 \\
\hline pBD2 & TGTCTGCCTCCTCTCTTCC & AACAGGTCCCTTCAATCCTG & AY506573.1 \\
\hline pBD3 & ССТTСТСТTTGССTTGСТСТT & GCCACTCACAGAACAGCTACC & XM_021074698.1 \\
\hline $\mathrm{pEP} 2 \mathrm{C}$ & ACTGCTTGTTCTCCAGAGCC & TGGCACAGATGACAAAGCCT & BK005522.1 \\
\hline IL-1 $\beta$ & AGAGGGACATGGAGAAGCGA & GCCCTCTGGGTATGGCTTT & NM_001302388.2 \\
\hline IL-6 & ATCAGGAGACCTGCTTGATG & TGGTGGCTTTGTCTGGATTC & NM_001252429.1 \\
\hline IL-8 & TCCTGCTTTCTGCAGCTCTC & GGGTGGAAAGGTGTGGAATG & NM_213867.1 \\
\hline $\mathrm{TNF}-\alpha$ & CTGTAGGTTGCTCCCACCTG & CCAGTAGGGCGGTTACAGAC & NM_214022.1 \\
\hline IL-10 & GGTTGCCAAGCCTTGTCAG & AGGCACTCTTCACСТССТC & NM_214041.1 \\
\hline TGF- $\beta$ & GAAGCGCATCGAGGCCATTC & GGCTCCGGTTCGACACTTTC & XM_021093503.1 \\
\hline TLR-1 & GTCAGTCAGCACCGCAGTAA & CAGACAAACTGGAGGGTGGT & NM_001031775 \\
\hline TLR-2 & TCACTTGTCTAACTTATCATCСТCT & TCAGCGAAGGTGTCATTATTGC & NM_213761.1 \\
\hline TLR-4 & GCCATCGCTGCTAACATCATC & CTCATACTCAAAGATACACCATCG & NM_001113039.2 \\
\hline NOD-1 & CTGTCGTCAACACCGATCCA & CCAGTTGGTGACGCAGCTT & $\mathrm{AB} 187219.1$ \\
\hline NOD-2 & CCTTTTGAAGATGCTGCCTG & GATTCTCTGCCCCATCGTAG & NM_001105295.1 \\
\hline
\end{tabular}

\section{Western blot analysis.}

After pretreatment with bacteria as described in adhesion assay section, IPEC-J2 cells were lysed using the RIPA Lysis Buffer (Beyotime, Shanghai, China) involving protease inhibitors. Protein concentrations were measured using the BCA Protein Assay Kit (Beyotime, Shanghai, China). Briefly, protein samples were separated by SDS-PAGE and transferred onto Polyvinylidene difluoride (PVDF) membranes (Millipore, MA, USA). Membranes with migrated proteins were blocked with $5 \%$ dried skimmed milk for $2 \mathrm{~h}$ at room temperature and incubated overnight at $4{ }^{\circ} \mathrm{C}$ with the following primary antibodies: claudin-1 (Abcam, Cambridge, UK), occluding (Abcam, Cambridge, UK), ERK1/2 (Cell Signaling Technology, MA, USA), phospho-ERK1/2 (Cell Signaling Technology, MA, USA), p38 (Cell Signaling Technology, MA, USA), phospho-p38 (Cell Signaling Technology, MA, USA), JNK (Cell Signaling Technology, MA, USA), phospho-JNK (Cell Signaling Technology, MA, USA), p65 (Cell Signaling Technology, MA, USA), phospho-p65 (Cell Signaling Technology, MA, USA), and $\beta$ actin (Abcam, Cambridge, UK). After being washed three times for five minutes using Tris-Buffered-Saline with Tween (TBST), membranes were incubated with horseradish peroxidase (HRP)-conjugated secondary antibodies for $1 \mathrm{~h}$ at room temperature. Then, protein bands were detected on an image system (Tanon, China) 
using the chemiluminescent HRP substrate kit (Millipore, MA, USA). Intensities of protein bands were determined using the Image J software. All experiments were performed in triplicate.

\section{Statistical Analysis.}

Experimental data were analyzed by IBM SPSS Statistics 20 and presented as mean \pm SD. Statistical significance between two groups was determined by two-tailed Student's $t$ test, while multiple comparisons were performed by one-way ANOVA. $P \leq 0.05$ was considered significant. Graphs were drawn using the OriginPro 2018 software.

\section{Results}

\section{L. plantarum Lac16 and its fermentation supernatant significantly inhibited the growth of $C$. perfringens.}

As shown in Fig. 1A, the positive group $(100 \mu \mathrm{g} / \mathrm{mL}$ of ampicillin) exhibited the best bacteriostatic effect on $C$. perfringens, with L. plantarum Lac16 fermentation supernatant also exhibiting good bacteriostatic effects, forming a clear boundary of bacteriostatic zone. In the biofilm formation experiment (Fig. 1B), after $12 \mathrm{~h}$ of culture, optical density $\left(\mathrm{OD}_{600}\right)$ of the $\mathrm{CP}$ group increased to $0.837 \pm 0.031$, while the $\mathrm{OD}_{600}$ of the control group was $0.090 \pm 0.002$, indicating that $C$. perfringens proliferated rapidly. However, in the group in which $C$. perfringens were co-incubated with the $L$. plantarum Lac16 fermentation supernatant, the $\mathrm{OD}_{600}$ only increased to $0.189 \pm 0.008$. These results indicate that $L$. plantarum Lac16 fermentation supernatant could significantly inhibit the growth of $C$. perfringens $(P<0.001)$. Similar results were obtained from the biofilm assays (Fig. $1 C)$. The $L$. plantarum Lac16 fermentation supernatant significantly inhibited the formation of $C$. perfringens biofilms when compared to the CP group $(P<0.001)$.

After that, we co-cultured L. plantarum Lac16 with C. perfringens and determined the corresponding $\mathrm{pH}$. It was found that CFUs of $C$. perfringens in the co-culture group were significantly decreased when compared to the CP group $(P<0.05)$ (Fig. 1D). Although L. plantarum Lac16 and $C$. perfringens could reduce the $\mathrm{pH}$ of the medium, the $\mathrm{pH}$ of Lac16 and co-culture groups were lower relative to those of the CP group $(P<0.01)($ Fig. 1F).

\section{L. plantarum Lac16 enhanced HDP mRNA expression in IPEC-J2 cells.}

Expression levels of HDP genes, including $p B D 1, p B D 2, p B D 3$ and $p E P 2 C$, were all found to be elevated after coincubation with L. plantarum Lac16 (Fig. 2). Specifically, expression levels of $p B D 1$ were significantly elevated after co-incubation with L. plantarum Lac16 at concentrations of $10^{7} \mathrm{CFU} / \mathrm{mL}$ and $10^{8} \mathrm{CFU} / \mathrm{mL}(P<0.001)$ (Fig. 2A). The best effect was obtained at the concentration of $10^{7} \mathrm{CFU} / \mathrm{mL}$. At the same time, the trend in $p B D 2$ gene expression level was similar (Fig. 2B), except that the group with a concentration of $10^{7} \mathrm{CFU} / \mathrm{mL}$ was the only one that exhibited a significant increase in gene expression $(P<0.05)$. Gene expression levels of $p B D 3$ and $p E P 2 C$ were significantly elevated in a concentration dependent manner after co-incubation with different concentrations of L. plantarum Lac16 ( $P<0.05$; Fig. 2C and D). To some extent, we found that $L$. plantarum Lac16 at elevated concentrations $\left(10^{8} \mathrm{CFU} / \mathrm{mL}\right)$ competed with cells for nutrients, therefore, we selected the medium concentration $\left(10^{7} \mathrm{CFU} / \mathrm{mL}\right)$ for the follow-up experiments.

\section{L. plantarum Lac16 alleviated $C$. perfringens infection-associated LDH leakage.}


Pretreatment with L. plantarum Lac16 did not increase LDH release in both groups $(P>0.05 ;$ Fig. 3A). However, when IPEC-J2 cells were infected with $C$. perfringens, LDH release was significantly elevated $(P<0.01)$, which was alleviated by pre-incubation with $L$. plantarum Lac16 $(P<0.01)$. However, the increased LDH release, which was associated with $C$. perfringens infection for $3 \mathrm{~h}$, was not alleviated to normal levels after $L$. plantarum Lac16 pre-incubation $(P<0.001)$, indicating cytotoxic induction due to the infection. Therefore, for subsequent experiments, we selected IPEC-J2 cells infected with $C$. perfringens for $1 \mathrm{~h}$ as the time point for sampling.

\section{L. plantarum Lac16 suppressed the adhesion of $C$. perfringens to IPEC-J2 cells.}

For the bacterial adhesion assay, we defined adhesion rate as $100 \%$ in the CP group, in which cells were only co-incubated with $C$. perfringens (Fig. 3B). However, when cells were pre-incubated with L. plantarum Lac16, the adhesion rate of $C$. perfringens to IPEC-J2 cells decreased significantly $(P<0.05)$. Similar results were obtained in the images of fluorescence labeling method (Fig. 3C). When IPEC-J2 cells were only infected with $C$. perfringens, the quantity of fluorescent labeled pathogens that adhered to cells was significantly larger than that of the group pretreated with L. plantarum Lac16.

\section{L. plantarum Lac16 attenuated $C$. perfringens-induced damage to intestinal barrier function.}

When IPEC-J2 cells developed tight junctions and were completely differentiated into tight monolayers, they were infected with $C$. perfringens. At the same time, the flux of fluorescein sodium significantly increased $(P<$ 0.001; Fig. 4A). However, L. plantarum Lac16 pretreatment significantly alleviated $C$. perfringens-induced increase in Papp of the IPEC-J2 monolayers $(P<0.001)$. Then, we evaluated the effects of bacterial pretreatment on the production of mucins (Fig. 4B). After PAS staining, it was found that $C$. perfringens infection inhibited mucin production. Moreover, $L$. plantarum Lac16 pretreatment effectively inhibited $C$. perfringens -mediated decrease in mucin production.

To evaluate $C$. perfringens-induced damage to intestinal epithelial barrier functions and the corresponding protective effects of L. plantarum Lac16, we determined the expression levels of tight junction proteins in IPECJ2 cells (Fig. 4C). Compared to the control group, there were no significant differences in expression levels of occludin in each group after incubation with bacteria $(P>0.05)$. However, $C$. perfringens significantly suppressed the expression levels of claudin-1 in IPEC-J2 cells $(P<0.01)$. L. plantarum Lac16 treatment significantly elevated the expressions of claudin-1 $(P<0.05)$ and alleviated the decrease in protein expressions caused by $C$. perfringens infection $(P<0.01)$. Regarding immunofluorescence images of ZO- 1 , we found that $L$. plantarum Lac16 pretreatment had no effect on protein expression levels, whereas $C$. perfringens infection significantly suppressed the expression of ZO-1 (Fig. 4D). At the same time, compared to the CP group, IPEC-J2 cells that had been co-incubated with L. plantarum Lac16 and $C$. perfringens exhibited increased expressions of ZO-1.

\section{L. plantarum Lac16 alleviated the increase in mRNA expression levels of PRRs after $C$. perfringens infection.}

mRNA expression levels of several PRRs in IPEC-J2 cells after co-incubation with L. plantarum Lac16 and $C$. perfringens were investigated (Fig. 5). Specifically, when cells had been co-incubated with bacteria, mRNA expression levels of TLRs were significantly up-regulated $(P<0.05)$ (Fig. 5A-C). The most significant increase in mRNA expression levels of TLRs was in the group infected with $C$. perfringens only. However, the increased mRNA expression (TLR1 and TLR2) caused by $C$. perfringens infection was effectively inhibited $(P<0.01)$ by 
co-incubation with L. plantarum Lac16. The trend in mRNA expression levels of NODs was similar to that of TLRs (Fig. 5D and E). Although both bacteria increased NOD1 gene expression $(P<0.001)$, preincubation with $L$. plantarum Lac16 significantly reduced the increased gene expression associated with $C$. perfringens infection $(P<0.01)$ (Fig. 5D). However, this effect was not significant in NOD2 gene expression $(P>0.05)($ Fig. $5 \mathrm{E})$.

\section{C. perfringens induced inflammatory effects through MAPK and NF-KB signaling pathways in IPEC-J2 cells.}

To investigate the potential signaling pathway that led to the release of inflammatory cytokines, phosphorylation levels of certain proteins of the MAPK and NF-KB were determined (Fig. 6). Specifically, $C$. perfringens infection enhanced the phosphorylation of $\mathrm{p} 38$, JNK, as well as $\mathrm{p} 65$ when compared to the control group $(P<0.05)$. Furthermore, ERK phosphorylation in each group did not change significantly $(P>0.05)$. Moreover, preincubation with L. plantarum Lac16 significantly inhibited $C$. perfringens infection-associated p65 phosphorylation $(P<0.001)$.

\section{L. plantarum Lac16 alleviated $C$. perfringens infection-associated increase in pro-inflammatory cytokine gene expression levels.}

We determined mRNA expression levels of inflammatory cytokines in IPEC-J2 cells after co-culture with bacteria (Fig. 7). After co-incubation with L. plantarum Lac16, mRNA expression levels of pro-inflammatory cytokines, such as interleukin (IL)-6 and $I L-8$, were significantly elevated $(P<0.05$; Fig. 7B and $C)$. At the same time, gene expression levels of pro-inflammatory cytokines, such as $I L-1 \beta, I L-6, I L-8$ and tumor necrosis factor (TNF)- $a$, were sharply elevated after $C$. perfringens infection $(P<0.001)$, which was significantly alleviated by preincubation with $L$. plantarum Lac16 $(P<0.05)$. L. plantarum Lac16 was very effective in alleviating the increase in $C$. perfringens infection-associated gene expressions of $I L-8$ and TNF- $a(P<0.001)$. Furthermore, when cells were respectively incubated with $L$. plantarum Lac16 or $C$. perfringens, gene expression levels of antiinflammatory cytokines, such as $I L-10$ and transforming growth factor (TGF)- $\beta$, did not change significantly ( $P>$ 0.05) (Fig. 7E and F). However, mRNA expression levels of anti-inflammatory cytokines in the Lac16+CP group decreased significantly when compared to the CP group $(P<0.05)$.

\section{Discussion}

Probiotics provide benefits to the host through various mechanisms, including producing anti-bacterial substances, competing with pathogenic microorganisms for enterocyte binding, regulating the secretion of proand anti-inflammatory cytokines, and maintaining intestinal barrier integrity [28]. There were several studies indicated that Lactobacillus spp. could resist the infection of pathogenic bacteria, including Escherichia coli, $C$. perfringens, and Salmonella Enteritidis [29, 30, 28, 15]. Previously, we found that L. plantarum Lac16 exhibits protective effects against $C$. perfringens infection in broilers [21]. In this study, we have shown that $L$. plantarum Lac16 inhibits the growth of $C$. perfringens and attenuates $C$. perfringens infection-associated intestinal injury in IPEC-J2 cells.

Probiotics exert antimicrobial activities by secreting antimicrobial substances, such as bacteriocins, organic acids, and hydrogen peroxide [31]. Cell-free supernatants containing antimicrobial substances secreted by probiotics effectively inhibit the growth of various pathogens [32]. In addition, $C$. perfringens strains form 
biofilms to enhance their persistence and increase resistance to various stressors, such as oxidative and antibiotic stress [33], and this phenomenon has been proved to be involved in a large proportion of bacterial infections [34]. In the current study, we found that the fermentation supernatant of L. plantarum Lac16 inhibited the growth of $C$. perfringens. Furthermore, the fermentation supernatant of L. plantarum Lac16 significantly suppressed $C$. perfringens biofilm formation. The antimicrobial activity of $L$. plantarum is associated with the production of organic acids, which decreases environmental $\mathrm{pH}$ [35]. C. perfringens is a $\mathrm{pH}$ sensitive bacterium [36]. Acidic environments downregulate the expression of virulence factors of $C$. perfringens while inhibiting its growth [36, 37]. These findings indicate that L. plantarum Lac16 and its metabolites decreased environmental $\mathrm{pH}$, and inhibited biofilm formation as well as the growth of $C$. perfringens.

HDPs, as important components of the innate immune system, play critical roles in infection resistance [38]. They are mainly secreted by intestinal epithelial cells and phagocytes in the gastrointestinal tract [24]. HDPs are involved in the maintenance of intestinal homeostasis and innate immune defenses during infection through multiple mechanisms. Specifically, HDPs secreted by intestinal epithelial cells exert direct antimicrobial effects on invading bacterial pathogens and intestinal microbiota [39]. There were several studies indicated that Lactobacillus spp. enhance the expression of HDPs [40-42]. In this study, we found that different concentrations of L. plantarum Lac16 promoted the expression of endogenous HDPs in IPEC-J2 cells. Increased secretion of endogenous HDPs improves early immune system responses to pathogenic infections and inflammation [43]. Our findings are consistent with those of Wang et al. who concluded that L. plantarum ZLP001 upregulates the expression of HDPs, and they also concluded that L. plantarum enhances intestinal defense responses by promoting the secretion of HDPs [24].

LDH is a stable cytoplasmic enzyme that possesses oxidation-reduction activities. When cells are subjected to cell membrane damage that is caused by intracellular or extracellular stress, LDH will rapidly release into the extracellular environment [44]. Alpha toxin, which is produced by $C$. perfringens type A, can result in extensive degradation of the plasma membrane, leading to LDH release [45]. Elevated LDH release is a key feature of apoptosis, necrosis, and other forms of cellular damage $[46,47]$. We found that $C$. perfringens infection elevated LDH release from IPEC-J2 cells, implying that $C$. perfringens damaged the intestinal epithelial cells, resulting in intracellular enzyme leakage. However, when cells were pre-incubated with L. plantarum Lac16, the C. perfringens infection-associated increase in LDH release was effectively alleviated. Similar protective results have been reported [48-51].

Pathogenic adherence to host epithelial cells is an indispensable step in the occurrence of infection [52]. In the meantime, Lactobacillus could effectively prevent pathogenic adhesion to intestinal epithelial cells and play an important role in maintaining intestinal homeostasis [53]. Thus, one way for Lactobacillus exerts its antibacterial activity is by occupying the adhesion site of pathogens to intestinal epithelial cells [54]. Probiotic adhesion to intestinal epithelial cells can optimize the balance and activities of intestinal microbiota [55]. It is worth mentioning that adherence of $C$. perfringens strains increases toxin production [56]. In this study, we found that L. plantarum Lac16 significantly suppressed $C$. perfringens adhesion to IPEC-J2 cells, thereby resisting $C$. perfringens infection and protecting intestinal epithelial cells. This finding is similar to that of another study, which showed that $L$. rhamnosus effectively inhibited the adhesion of $C$. perfringens to pig intestinal mucosa [57]. 
Epithelial cells form a layer that acts as a physical barrier connected by tight junctions between each cell [58]. The main components of tight junction proteins are claudins, zona occludens, and occludin [59]. Tight junctions regulate paracellular transport of various substances, such as ions, solutes, molecules, and water across the intestinal epithelium [60], thereby maintaining physiological functions of epithelial cells [61]. Probiotics and pathogens can alter the expression of tight junctions [61, 62]. Moreover, dysregulation of tight junction protein integrity enhances intestinal barrier permeability [63]. It is worth noting that virulence factors produced by $C$. perfringens, such as $C$. perfringens enterotoxins, can effectively impair tight junctions $[9,64]$. In this study, C. perfringens infection suppressed the expression levels of claudin-1 and ZO-1, thereby increasing intestinal barrier permeability. However, these effects were effectively alleviated by L. plantarum Lac16 preincubation. In addition, the mucus layer covering the surface of intestinal epithelium plays a crucial role in protecting intestinal epithelial barrier integrity [65]. We found that L. plantarum Lac16 preincubation attenuated C. perfringens-induced disruption of mucus production. Our results are consistent with those of studies reporting on the effects of probiotics in the alleviation of intestinal barrier dysfunction caused by pathogens $[65,66,28]$.

PRRs, including TLRs and NOD-like receptors (NLRs), are important receptor molecules in host immune system [67]. PRRs play a crucial protective role in the immune system via identifying pathogen-associated molecular patterns (PAMPs), such as bacterial nucleic acids and flagellin, to resist pathogenic infections [68].

Furthermore, PRRs initiate the activation of intracellular signaling pathways, thereby increasing the expression and release of chemokines, cytokines and antibacterial peptides [69]. It is worth mentioning that TLRs play a crucial role in regulation of mucosal immune responses and maintenance of intestinal homeostasis [70]. In the current study, we found that $L$. plantarum Lac16 elevated the expression levels of TLRs. Changes in expression levels of TLRs in intestinal epithelial cells regulate $\beta$-defensin expression [71], corresponding to our previous conclusion that $L$. plantarum Lac16 enhances the expression of endogenous HDPs. The $C$. perfringens challenge sharply elevated the mRNA expression levels of TLRs, including TLR1, TLR2, and TLR4, whereas preincubation with $L$. plantarum Lac16 attenuated this dramatic increase. When pathogens gain entry into the cytoplasm, NLRs have been shown initiate innate immune responses [72]. We found that $L$. plantarum Lac16 alleviated $C$. perfringens-induced elevations in NOD1 expression, in tandem with other studies that reported that probiotics attenuate pathogen associated elevations in PRR expression $[73,28]$. In our opinion, L. plantarum Lac16 activates PRR-dependent signaling pathways and strengthens the immune system to resist $C$. perfringens infection.

MAPK signaling pathways are signal transduction modules that transform extracellular signals into intracellular responses that regulate the processes of cell growth, differentiation, and migration $[74,75]$. In addition, MAPK play a crucial role in modulating the synthesis and release of inflammatory mediators during inflammatory responses [76, 77]. Elevated expressions of PRRs enhance the phosphorylation of MAPK [78, 79]. In this study, C. perfringens infection significantly elevated p38 and JNK phosphorylation in IPEC-J2 cells. However, preincubation with L. plantarum Lac16 did not significantly attenuate these phenomena. We indicated that $C$. perfringens-induced inflammatory responses are partly mediated by MAPK signaling pathways.

$\mathrm{NF}-\mathrm{KB}$, an important transcription factor, is a key factor for modulating the expression of genes and proteins involved in inflammatory responses [80]. For example, production of proinflammatory cytokines, such as TNF-a, are closely associated with activation of NF-KB [81]. Probiotics have also been shown to exert their protective

Page 12/24 
mechanisms against pathogenic infections by modulating the NF-KB signaling pathways $[82,83,28]$. In this study, preincubation with $L$. plantarum Lac16 significantly attenuated $C$. perfringens-induced increase in p65 phosphorylation, implying that $L$. plantarum Lac16 prevents $C$. perfringens infection-associated excess immune responses by attenuating $\mathrm{p} 65$ phosphorylation.

Infections with pathogenic microbes, such as $C$. perfringens, often leads to significant inflammatory responses $[84,85]$. Pro-inflammatory cytokines mediate inflammatory responses to invading pathogens through multiple modulatory mechanisms, such as lymphocyte activation, neutrophil migration, and cell proliferation [86]. However, excess secretion of pro-inflammatory cytokines has deleterious effects on the host [87]. In this study, although $L$. plantarum Lac16 elevated the expression levels of pro-inflammatory cytokines, such as IL-6 and IL8, preincubation with $L$. plantarum Lac16 significantly inhibited $C$. perfringens associated inflammatory responses. In our previous study involving broilers, we found similar protective effects, whereby L. plantarum Lac16 alleviated $C$. perfringens infection-associated inflammatory responses in the ileum mucosa [21]. In general, we postulate that one of the mechanisms through which L. plantarum Lac16 protects intestinal epithelial cells from $C$. perfringens injury is by relieving inflammation. Interestingly, when intestinal epithelial cells were incubated with $L$. plantarum Lac16 or $C$. perfringens, mRNA expression levels of anti-inflammatory cytokines were not significantly altered, while expression levels in the Lac16 + Cp group were significantly suppressed. These findings should be confirmed in more studies.

\section{Conclusions}

In summary, our study used a model system of IPEC-J2 cells to indicate the protective effects of L. plantarum Lac16 via several mechanisms against $C$. perfringens infection, including suppressing the growth and biofilm formation abilities of $C$. perfringens, reducing $\mathrm{pH}$ levels in the environment, preventing pathogenic adhesion to epithelial cells, promoting the expressions of endogenous host defense peptides, protecting intestinal epithelial barrier integrity, and alleviating inflammatory responses by attenuating p 65 phosphorylation. These findings highlight the significance of $L$. plantarum Lac16 as a potential therapeutic strategy against $C$. perfringens infection and provide a theoretical basis for the application of $L$. plantarum Lac16 in animal husbandry to resist pathogen infections.

\section{Abbreviations}

BSA: Bovine serum albumin; CFU: Colony forming units; C. perfringens: Clostridium perfringens; DAPI: 4',6Diamidino-2-phenylindole dihydrochloride; DMEM/F12: Dulbecco's modified Eagle's F12 ham medium; FBS: Fetal bovine serum; FITC: Fluorescein isothiocyanate; HDPs: Host defense peptides; HRP: Horseradish peroxidase; LDH: Lactate dehydrogenase; IL: Interleukin; IPEC-J2: Intestinal porcine epithelial cell line; $L$. plantarum: Lactobacillus plantarum; MAPK: Mitogen-activated protein kinase; MRS: Mann-Rogosa-Sharpe; NFKB: Nuclear factor-KB; NLRs: NOD-like receptors; NOD: Nucleotide-binding oligomerization domain; OD: Optical density; PAMPs: Pathogen-associated molecular patterns; Papp: Apparent permeability coefficient; PAS: Periodic acid-Schiff; pBD: Porcine $\beta$-defensin; PBS: Phosphate-buffered saline; PCR: Polymerase chain reaction; pEP2C: Porcine epididymis protein 2 splicing variant C; PRRs: Pattern recognition receptors; PVDF: Polyvinylidene difluoride; RCM: Reinforced clostridium medium; TBST: Tris-Buffered-Saline with Tween; TGF: 
transforming growth factor; TLR: Toll-like receptor; TNF-a: Tumor necrosis factor-a; TSC: Tryptose sulfite cycloserine; ZO-1: Zona occludens 1

\section{Declarations}

\section{Availability of data and materials}

All data generated or analyzed during this study are available from the corresponding author by request.

\section{Authors' contributions}

$W L, Y Z$, and LG conceptualized the experiments; $Y Z$ performed the experiments, analyzed the data and wrote the original draft; BK and the rest of the authors revised the manuscript. All authors have read and agreed to the published version of the manuscript.

\section{Funding}

This study is supported by the Natural Science Foundation of Zhejiang province, China (No. LZ20C170002), the National Natural Science Foundation of China (No. 32072766ه31672460, and 31472128), National High-Tech R\&D Program (863) of China (No. 2013AA102803D), the Major Science and Technology Project of Zhejiang Province (No. 2006C12086), PRC.

\section{Acknowledgements}

The authors would like to thank members of their laboratory for helpful and constructive advice.

\section{Competing interests}

The authors declare that they have no competing interests.

\section{Ethics approval and consent to participate}

Not applicable.

\section{Consent for publication}

Not applicable.

\section{References}

1. O'Brien DK, Melville SB. Effects of Clostridium perfringens alpha-toxin (PLC) and perfringolysin O (PFO) on cytotoxicity to macrophages, on escape from the phagosomes of macrophages, and on persistence of $\mathrm{C}$. perfringens in host tissues. Infect Immun. 2004;72(9):5204-15.

2. Hassan KA, Elbourne LD, Tetu SG, Melville SB, Rood JI, Paulsen IT. Genomic analyses of Clostridium perfringens isolates from five toxinotypes. Res Microbiol. 2015;166(4):255-63.

3. Songer JG. Clostridial enteric diseases of domestic animals. Clin Microbiol Rev. 1996;9(2):216-34. 
4. Revitt-Mills SA, Rood JI, Adams V. Clostridium perfringens extracellular toxins and enzymes: 20 and counting. Microbiol Aust. 2015;36(3):114-7.

5. Shojadoost B, Vince AR, Prescott JF. The successful experimental induction of necrotic enteritis in chickens by Clostridium perfringens: a critical review. Vet Res. 2012;43:74.

6. Petit L, Gibert M, Popoff MR. Clostridium perfringens: toxinotype and genotype. Trends Microbiol. 1999;7(3):104-10.

7. Kiu R, Hall LJ. An update on the human and animal enteric pathogen Clostridium perfringens. Emerg Microbes Infect. 2018;7(1):141.

8. Nedbalcová K, Zouharová M. Resistance of isolates of Clostridium perfringens type a from pig management in the Czech Republic to the selected antimicrobials. Veterinářství. 2018;68(9):640-4.

9. Luo RR, Yang QL, Huang XY, Yan ZQ, Gao XL, Wang W et al. Clostridium perfringens beta2 toxin induced in vitro oxidative damage and its toxic assessment in porcine small intestinal epithelial cell lines. Gene. 2020;759.

10. Posthaus $H$, Kittl S, Tarek B, Bruggisser J. Clostridium perfringens type $C$ necrotic enteritis in pigs: diagnosis, pathogenesis, and prevention. J Vet Diagn Invest. 2020;32(2):203-12.

11. Reid G, Jass J, Sebulsky MT, McCormick JK. Potential uses of probiotics in clinical practice. Clinical microbiology reviews. 2003;16(4):658-72.

12. Zhou YH, Zeng ZH, Xu YB, Ying JF, Wang BK, Majeed M et al. Application of Bacillus coagulans in Animal Husbandry and Its Underlying Mechanisms. Animals-Basel. 2020;10(3).

13. Wang JQ, Yin FG, Zhu C, Yu H, Niven SJ, de Lange CFM et al. Evaluation of probiotic bacteria for their effects on the growth performance and intestinal microbiota of newly-weaned pigs fed fermented highmoisture maize. Livest Sci. 2012;145(1-3):79-86.

14. Hao QK, Dong BR, Wu TX. Probiotics for preventing acute upper respiratory tract infections. Cochrane Db Syst Rev. 2015(2).

15. Guo S, Liu D, Zhang B, Li Z, Li Y, Ding B et al. Two Lactobacillus Species Inhibit the Growth and alpha-Toxin Production of Clostridium perfringens and Induced Proinflammatory Factors in Chicken Intestinal Epithelial Cells in Vitro. Front Microbiol. 2017;8:2081.

16. Allaart JG, van Asten AJ, Vernooij JC, Grone A. Effect of Lactobacillus fermentum on beta2 toxin production by Clostridium perfringens. Appl Environ Microbiol. 2011;77(13):4406-11.

17. Li Z, Wang W, Liu D, Guo Y. Effects of Lactobacillus acidophilus on the growth performance and intestinal health of broilers challenged with Clostridium perfringens. J Anim Sci Biotechnol. 2018;9:25.

18. Xu T, Chen Y, Yu L, Wang J, Huang M, Zhu N. Effects of Lactobacillus plantarum on intestinal integrity and immune responses of egg-laying chickens infected with Clostridium perfringens under the free-range or the specific pathogen free environment. BMC Vet Res. 2020;16(1):47.

19. Kizerwetter-Swida M, Binek M. Protective effect of potentially probiotic Lactobacillus strain on infection with pathogenic bacteria in chickens. Pol J Vet Sci. 2009;12(1):15-20.

20. Cao L, Yang XJ, Li ZJ, Sun FF, Wu XH, Yao JH. Reduced lesions in chickens with Clostridium perfringensinduced necrotic enteritis by Lactobacillus fermentum 1.20291. Poult Sci. 2012;91(12):3065-71. 
21. Gong L, Wang B, Zhou Y, Tang L, Zeng Z, Zhang H et al. Protective Effects of Lactobacillus plantarum 16 and Paenibacillus polymyxa 10 Against Clostridium perfringens Infection in Broilers. Frontiers in Immunology. 2020;11.

22. Liu HY, Roos S, Jonsson H, Ahl D, Dicksved J, Lindberg JE et al. Effects of Lactobacillus johnsonii and Lactobacillus reuteri on gut barrier function and heat shock proteins in intestinal porcine epithelial cells. Physiological Reports. 2015;3(4).

23. Brosnahan AJ, Brown DR. Porcine IPEC-J2 intestinal epithelial cells in microbiological investigations. Vet Microbiol. 2012;156(3-4):229-37.

24. Wang J, Zeng Y, Wang S, Liu H, Zhang D, Zhang W et al. Swine-Derived Probiotic Lactobacillus plantarum Inhibits Growth and Adhesion of Enterotoxigenic Escherichia coli and Mediates Host Defense. Front Microbiol. 2018;9:1364.

25. Jiang Y, Kong Q, Roland KL, Wolf A, Curtiss R, 3rd. Multiple effects of Escherichia coli Nissle 1917 on growth, biofilm formation, and inflammation cytokines profile of Clostridium perfringens type A strain CP4. Pathog Dis. 2014;70(3):390-400.

26. Nie Y, Hu J, Hou Q, Zheng W, Zhang X, Yang T et al. Lactobacillus frumenti improves antioxidant capacity via nitric oxide synthase 1 in intestinal epithelial cells. The FASEB Journal. 2019;33(10):10705-16.

27. Livak KJ, Schmittgen TD. Analysis of relative gene expression data using real-time quantitative PCR and the 2- $\Delta \Delta$ CT method. methods. 2001;25(4):402-8.

28. Qiao J, Sun Z, Liang D, Li H. Lactobacillus salivarius alleviates inflammation via NF-kappaB signaling in ETEC K88-induced IPEC-J2 cells. J Anim Sci Biotechnol. 2020;11:76.

29. Chen L, Guanglin J, Ying Q, Kang S, Yan M, Pengyan W et al. Effect of Pig Lactobacillus to Salmonella, Escherichia coli Adhesion on Pig Small Intestinal Epithelial Cell. Acta Agriculturae Boreali-Occidentalis Sinica. 2013:09.

30. Muyyarikkandy MS, Amalaradjou MA. Lactobacillus bulgaricus, Lactobacillus rhamnosus and Lactobacillus paracasei Attenuate Salmonella Enteritidis, Salmonella Heidelberg and Salmonella Typhimurium Colonization and Virulence Gene Expression In Vitro. Int J Mol Sci. 2017;18(11).

31. Khaneghah AM, Abhari K, Es I, Soares MB, Oliveira RBA, Hosseini H et al. Interactions between probiotics and pathogenic microorganisms in hosts and foods: A review. Trends Food Sci Tech. 2020;95:205-18.

32. Geraldo BMC, Batalha MN, Milhan NVM, Rossoni RD, Scorzoni L, Anbinder AL. Heat-killed Lactobacillus reuteri and cell-free culture supernatant have similar effects to viable probiotics during interaction with Porphyromonas gingivalis. J Periodontal Res. 2020;55(2):215-20.

33. Varga JJ, Therit B, Melville SB. Type IV Pili and the CcpA Protein Are Needed for Maximal Biofilm Formation by the Gram-Positive Anaerobic Pathogen Clostridium perfringens. Infection and Immunity. 2008;76(11):4944-51.

34. Biel MA. Photodynamic therapy of bacterial and fungal biofilm infections. Photodynamic Therapy. Springer; 2010. p. 175-94.

35. Oldak A, Zielinska D, Rzepkowska A, Kolozyn-Krajewska D. Comparison of Antibacterial Activity of Lactobacillus plantarum Strains Isolated from Two Different Kinds of Regional Cheeses from Poland: Oscypek and Korycinski Cheese. Biomed Res Int. 2017;2017:6820369. 
36. Li J, McClane BA. Comparative effects of osmotic, sodium nitrite-induced, and $\mathrm{pH}$-induced stress on growth and survival of Clostridium perfringens type $A$ isolates carrying chromosomal or plasmid-borne enterotoxin genes. Appl Environ Microbiol. 2006;72(12):7620-5.

37. Adachi K, Ohtani K, Kawano M, Singh RP, Yousuf B, Sonomoto K et al. Metabolic dependent and independent pH-drop shuts down VirSR quorum sensing in Clostridium perfringens. J Biosci Bioeng. 2018;125(5):525-31.

38. Hancock REW, Sahl HG. Antimicrobial and host-defense peptides as new anti-infective therapeutic strategies. Nat Biotechnol. 2006;24(12):1551-7.

39. Blyth GA, Connors L, Fodor C, Cobo ER. The network of colonic host defense peptides as an innate immune defense against enteropathogenic bacteria. Frontiers in Immunology. 2020;11.

40. Zhang J, Deng J, Li Y, Yang Q. The effect of Lactobacillus on the expression of porcine $\beta$-defensin-2 in the digestive tract of piglets. Livest Sci. 2011;138(1-3):259-65.

41. Liu HB, Hou CL, Wang G, Jia HM, Yu HT, Zeng XF et al. Lactobacillus reuteri I5007 Modulates Intestinal Host Defense Peptide Expression in the Model of IPEC-J2 Cells and Neonatal Piglets. Nutrients. 2017;9(6).

42. Wang J, Zhang W, Wang SX, Liu H, Zhang DY, Wang YM et al. Swine-Derived Probiotic Lactobacillus plantarum Modulates Porcine Intestinal Endogenous Host Defense Peptide Synthesis Through TLR2/MAPK/AP-1 Signaling Pathway. Frontiers in Immunology. 2019;10.

43. Veldhuizen EJ, Rijnders M, Claassen EA, van Dijk A, Haagsman HP. Porcine beta-defensin 2 displays broad antimicrobial activity against pathogenic intestinal bacteria. Mol Immunol. 2008;45(2):386-94.

44. Kumar P, Nagarajan A, Uchil PD. Analysis of Cell Viability by the Lactate Dehydrogenase Assay. Cold Spring Harb Protoc. 2018;2018(6).

45. Navarro MA, McClane BA, Uzal FA. Mechanisms of Action and Cell Death Associated with Clostridium perfringens Toxins. Toxins (Basel). 2018;10(5).

46. Chan FK, Moriwaki K, De Rosa MJ. Detection of necrosis by release of lactate dehydrogenase activity. Methods Mol Biol. 2013;979:65-70.

47. Rayamajhi M, Zhang Y, Miao EA. Detection of pyroptosis by measuring released lactate dehydrogenase activity. Methods Mol Biol. 2013;1040:85-90.

48. Mazkour S, Shekarforoush SS, Basiri S, Nazifi S, Yektaseresht A, Honarmand M. Effects of two probiotic spores of Bacillus species on hematological, biochemical, and inflammatory parameters in Salmonella Typhimurium infected rats. Sci Rep. 2020;10(1):8035.

49. Wu Q, Zhu Y-H, Xu J, Liu X, Duan C, Wang M-J et al. Lactobacillus rhamnosus GR-1 Ameliorates Escherichia coli-induced Activation of NLRP3 and NLRC4 Inflammasomes with Differential Requirement for ASC. Frontiers in microbiology. 2018;9:1661.

50. Qiao Z, Chen J, Zhou Q, Wang X, Shan Y, Yi Y et al. Purification, characterization, and mode of action of a novel bacteriocin BM173 from Lactobacillus crustorum MN047 and its effect on biofilm formation of Escherichia coli and Staphylococcus aureus. J Dairy Sci. 2021;104(2):1474-83.

51. Wang B, Hussain A, Zhou Y, Zeng Z, Wang Q, Zou P et al. Saccharomyces boulardii attenuates inflammatory response induced by Clostridium perfringens via TLR4/TLR15-MyD8 pathway in HD11 avian macrophages. Poult Sci. 2020;99(11):5356-65. 
52. Collado MC, Gueimonde M, Salminen S. Probiotics in adhesion of pathogens: mechanisms of action. Bioactive Foods in Promoting Health. Elsevier; 2010. p. 353-70.

53. Gudina EJ, Fernandes EC, Teixeira JA, Rodrigues LR. Antimicrobial and anti-adhesive activities of cellbound biosurfactant from Lactobacillus agilis CCUG31450. Rsc Adv. 2015;5(110):90960-8.

54. Salminen S, Nybom S, Meriluoto J, Collado MC, Vesterlund S, El-Nezami H. Interaction of probiotics and pathogens-benefits to human health? Curr Opin Biotech. 2010;21(2):157-67.

55. Liu WC, Devi S, Park J, Kim I. Effects of complex probiotic supplementation in growing pig diets with and without palm kernel expellers on growth performance, nutrient digestibility, blood parameters, fecal microbial shedding and noxious gas emission. Anim Sci J. 2018;89(3):552-60.

56. McClane BA. Clostridium perfringens type $C$ isolates rapidly upregulate their toxin production upon contact with host cells New insights into virulence? Virulence. 2010;1(2):97-100.

57. Collado MC, Grzeskowiak L, Salminen S. Probiotic strains and their combination inhibit in vitro adhesion of pathogens to pig intestinal mucosa. Curr Microbiol. 2007;55(3):260-5.

58. Chelakkot C, Ghim J, Ryu SH. Mechanisms regulating intestinal barrier integrity and its pathological implications. Exp Mol Med. 2018;50.

59. Hartsock A, Nelson WJ. Adherens and tight junctions: Structure, function and connections to the actin cytoskeleton. Bba-Biomembranes. 2008;1778(3):660-9.

60. Lee B, Moon KM, Kim CY. Tight Junction in the Intestinal Epithelium: Its Association with Diseases and Regulation by Phytochemicals. J Immunol Res. 2018;2018.

61. Awad WA, Hess C, Hess M. Enteric Pathogens and Their Toxin-Induced Disruption of the Intestinal Barrier through Alteration of Tight Junctions in Chickens. Toxins. 2017;9(2).

62. Blackwood BP, Yuan CY, Wood DR, Nicolas JD, Grothaus JS, Hunter CJ. Probiotic Lactobacillus Species Strengthen Intestinal Barrier Function and Tight Junction Integrity in Experimental Necrotizing Enterocolitis. J Probiotics Health. 2017;5(1).

63. Che S-y, Yuan J-w, Zhang L, Ruan Z, Sun X-m, Lu H. Puerarin prevents epithelial tight junction dysfunction induced by ethanol in Caco-2 cell model. Journal of Functional Foods. 2020;73:104079.

64. Eichner M, Protze J, Piontek A, Krause G, Piontek J. Targeting and alteration of tight junctions by bacteria and their virulence factors such as Clostridium perfringens enterotoxin. Pflug Arch Eur J Phy. 2017;469(1):77-90.

65. Fan HY, Chen ZH, Lin RQ, Liu YY, Wu XB, Puthiyakunnon S et al. Bacteroides fragilis Strain ZY-312 Defense against Cronobacter sakazakii-Induced Necrotizing Enterocolitis In Vitro and in a Neonatal Rat Model. Msystems. 2019;4(4).

66. Xiao Z, Liu L, Tao W, Pei X, Wang G, Wang M. Clostridium tyrobutyricum protect intestinal barrier function from LPS-induced apoptosis via p38/JNK signaling pathway in IPEC-J2 cells. J Anim Sci. 2018;96:166-7.

67. Xiao Y, Yan H, Diao H, Yu B, He J, Yu J et al. Early Gut Microbiota Intervention Suppresses DSS-Induced Inflammatory Responses by Deactivating TLR/NLR Signalling in Pigs. Sci Rep. 2017;7(1):3224.

68. Kamada N, Seo SU, Chen GY, Nunez G. Role of the gut microbiota in immunity and inflammatory disease. Nat Rev Immunol. 2013;13(5):321-35. 
69. Wellnitz O, Bruckmaier RM. The innate immune response of the bovine mammary gland to bacterial infection. Vet J. 2012;192(2):148-52.

70. Miyake K. Innate immune sensing of pathogens and danger signals by cell surface Toll-like receptors. Semin Immunol. 2007;19(1):3-10.

71. Vora P, Youdim A, Thomas LS, Fukata M, Tesfay SY, Lukasek K et al. $\beta$-defensin-2 expression is regulated by TLR signaling in intestinal epithelial cells. The Journal of Immunology. 2004;173(9):5398-405.

72. Brubaker SW, Bonham KS, Zanoni I, Kagan JC. Innate immune pattern recognition: a cell biological perspective. Annu Rev Immunol. 2015;33:257-90.

73. Wu Q, Liu MC, Yang J, Wang JF, Zhu YH. Lactobacillus rhamnosus GR-1 Ameliorates Escherichia coliInduced Inflammation and Cell Damage via Attenuation of ASC-Independent NLRP3 Inflammasome Activation. Appl Environ Microbiol. 2016;82(4):1173-82.

74. Coulombe P, Meloche S. Atypical mitogen-activated protein kinases: structure, regulation and functions. Biochim Biophys Acta. 2007;1773(8):1376-87.

75. Zhu Z, Xueying L, Chunlin L, Wen X, Rongrong Z, Jing $\mathrm{H}$ et al. Effect of berberine on LPS-induced expression of NF-K B/MAPK signalling pathway and related inflammatory cytokines in porcine intestinal epithelial cells. Innate Immunity. 2020;26(7):627-34.

76. Qi F, Bai S, Wang D, Xu L, Hu H, Zeng S et al. Macrophages produce IL-33 by activating MAPK signaling pathway during RSV infection. Mol Immunol. 2017;87:284-92.

77. Qi M, Elion EA. MAP kinase pathways. J Cell Sci. 2005;118(Pt 16):3569-72.

78. Conti F, Boucherit N, Baldassarre V, Trouplin V, Toman R, Mottola G et al. Coxiella burnetii lipopolysaccharide blocks p38a-MAPK activation through the disruption of TLR-2 and TLR-4 association. Frontiers in cellular and infection microbiology. 2015;4:182.

79. Lee J, Kim HJ, Nguyen TTH, Kim SC, Ree J, Choi TG et al. Emodin 8-0-glucoside primes macrophages more strongly than emodin aglycone via activation of phagocytic activity and TLR-2/MAPK/NF-KB signalling pathway. International Immunopharmacology. 2020;88:106936.

80. Vallabhapurapu S, Karin M. Regulation and function of NF-kappaB transcription factors in the immune system. Annu Rev Immunol. 2009;27:693-733.

81. Tak PP, Firestein GS. NF-kappaB: a key role in inflammatory diseases. J Clin Invest. 2001;107(1):7-11.

82. Yin HJ, Ye PF, Lei QZ, Cheng YD, Yu H, Du JJ et al. In vitro probiotic properties of Pediococcus pentosaceus L1 and its effects on enterotoxigenic Escherichia coli-induced inflammatory responses in porcine intestinal epithelial cells. Microb Pathogenesis. 2020;144.

83. Xia B, Yu J, He T, Liu X, Su JH, Wang MJ et al. Lactobacillus johnsonii L531 ameliorates enteritis via elimination of damaged mitochondria and suppression of SQSTM1-dependent mitophagy in a Salmonella infantis model of piglet diarrhea. Faseb J. 2020;34(2):2821-39.

84. Zhang B, Gan L, Shahid MS, Lv Z, Fan H, Liu D et al. In vivo and in vitro protective effect of arginine against intestinal inflammatory response induced by Clostridium perfringens in broiler chickens. J Anim Sci Biotechnol. 2019;10:73.

85. Bortoluzzi C, Lumpkins B, Mathis GF, Franca M, King WD, Graugnard DE et al. Zinc source modulates intestinal inflammation and intestinal integrity of broiler chickens challenged with coccidia and Clostridium perfringens. Poult Sci. 2019;98(5):2211-9. 
86. Nguyen TTT, Nguyen HT, Wang P-C, Chen S-C. Identification and expression analysis of two proinflammatory cytokines, TNF- $a$ and IL-8, in cobia (Rachycentron canadum L.) in response to Streptococcus dysgalactiae infection. Fish \& shellfish immunology. 2017;67:159-71.

87. Ertel W, Kremer JP, Kenney J, Steckholzer U, Jarrar D, Trentz 0 et al. Downregulation of proinflammatory cytokine release in whole blood from septic patients. Blood. 1995;85(5):1341-7.

\section{Figures}
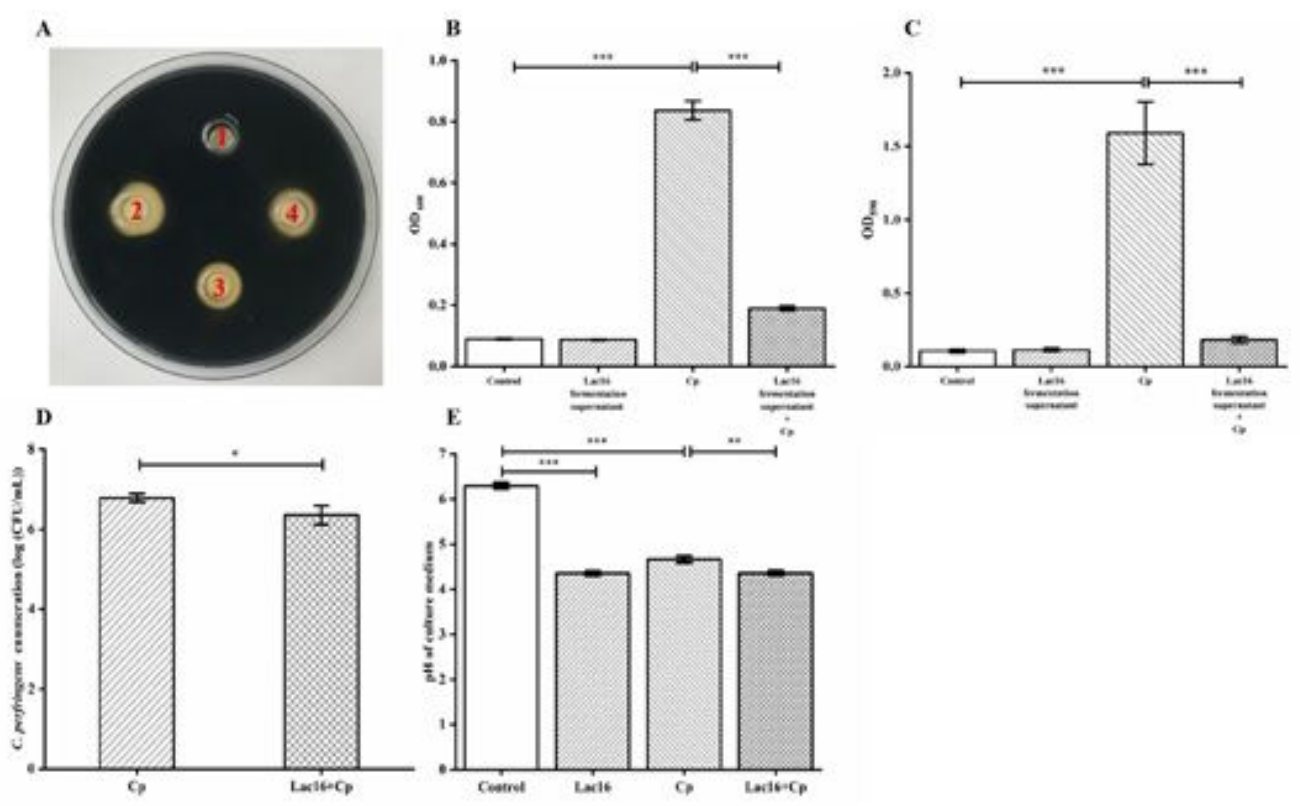

\section{Figure 1}

Antimicrobial activity of L. plantarum Lac16 on C. perfringens. (A) Agar well diffusion assay. 1: MRS broth; 2: $100 \mu \mathrm{g} / \mathrm{mL}$ of ampicillin; 3 and 4: L. plantarum Lac16 fermentation supernatant. (B) The growth of C. perfringens in different groups was measured by OD600 after $12 \mathrm{~h}$ of incubation. (C) Biofilm formation was measured by OD590. (D) C. perfringens levels in the co-culture experiment. (E) $\mathrm{pH}$ values of cultures in different groups. Data are presented as the means $\pm S D$ for $n=3$; ${ }^{P}<0.05$, ${ }^{\star *} P<0.01$, $* \star * P<0.001$ (t test). 

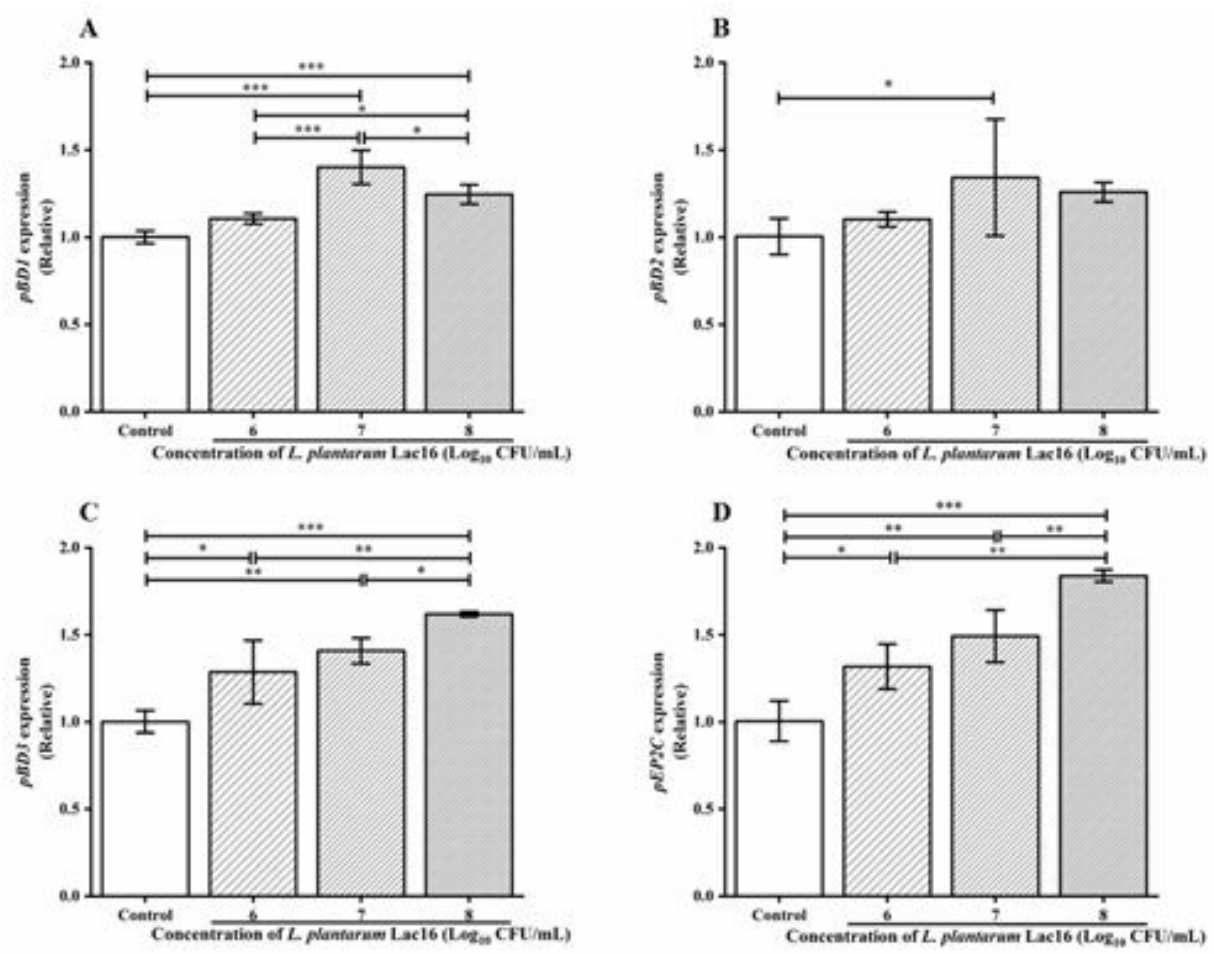

\section{Figure 2}

Gene expression levels of HDPs in L. plantarum Lac16 treated IPEC-J2 cells. (A) pBD1, (B) pBD2, (C) pBD3, (D) pEP2C. mRNA expression was standardized to $\beta$-actin expression. Data are presented as the means \pm SD for $n$ $=3 ; * \mathrm{P}<0.05,{ }^{* *} \mathrm{P}<0.01$, *** $\mathrm{P}<0.001$ (one-way ANOVA).
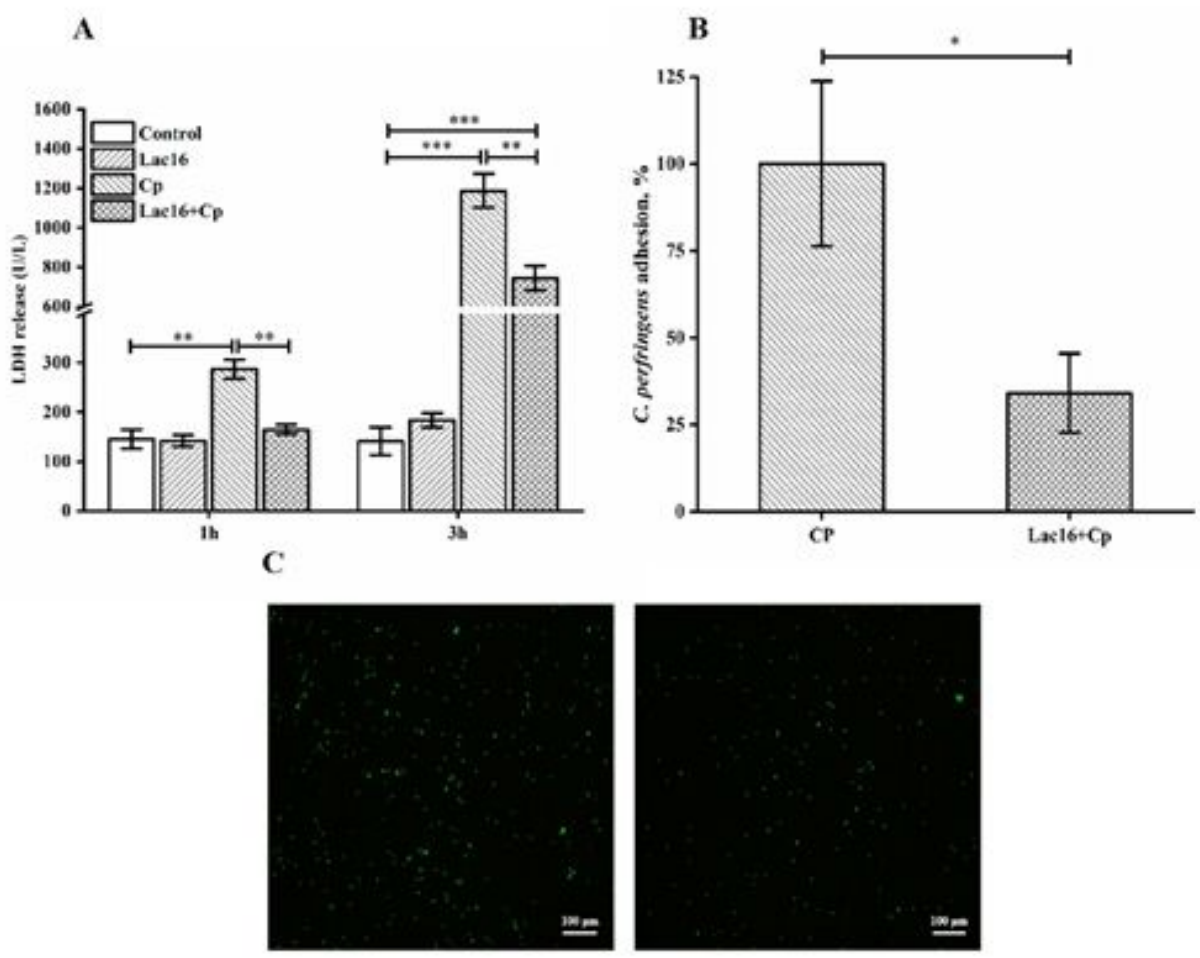

$C_{\mathrm{p}}$

Lac16+Cp

Figure 3 
Cytotoxicity and C. Perfringens adhesion assays. (A) Concentrations of LDH in the supernatants of IPEC-J2 cells. (B) Adhesions of C. perfringens to IPEC-J2 cells were detected by on the TSC agar. Adherence ratio of the C. perfringens group was normalized to $100 \%$. (C) Adhesions of C. perfringens (green) to IPEC-J2 cells were detected by fluorescence labeling method. Data are presented as the means \pm SD for $n=3$; * $P<0.05$, ** $P<$ $0.01, * \star \star P<0.001$ ( t test).
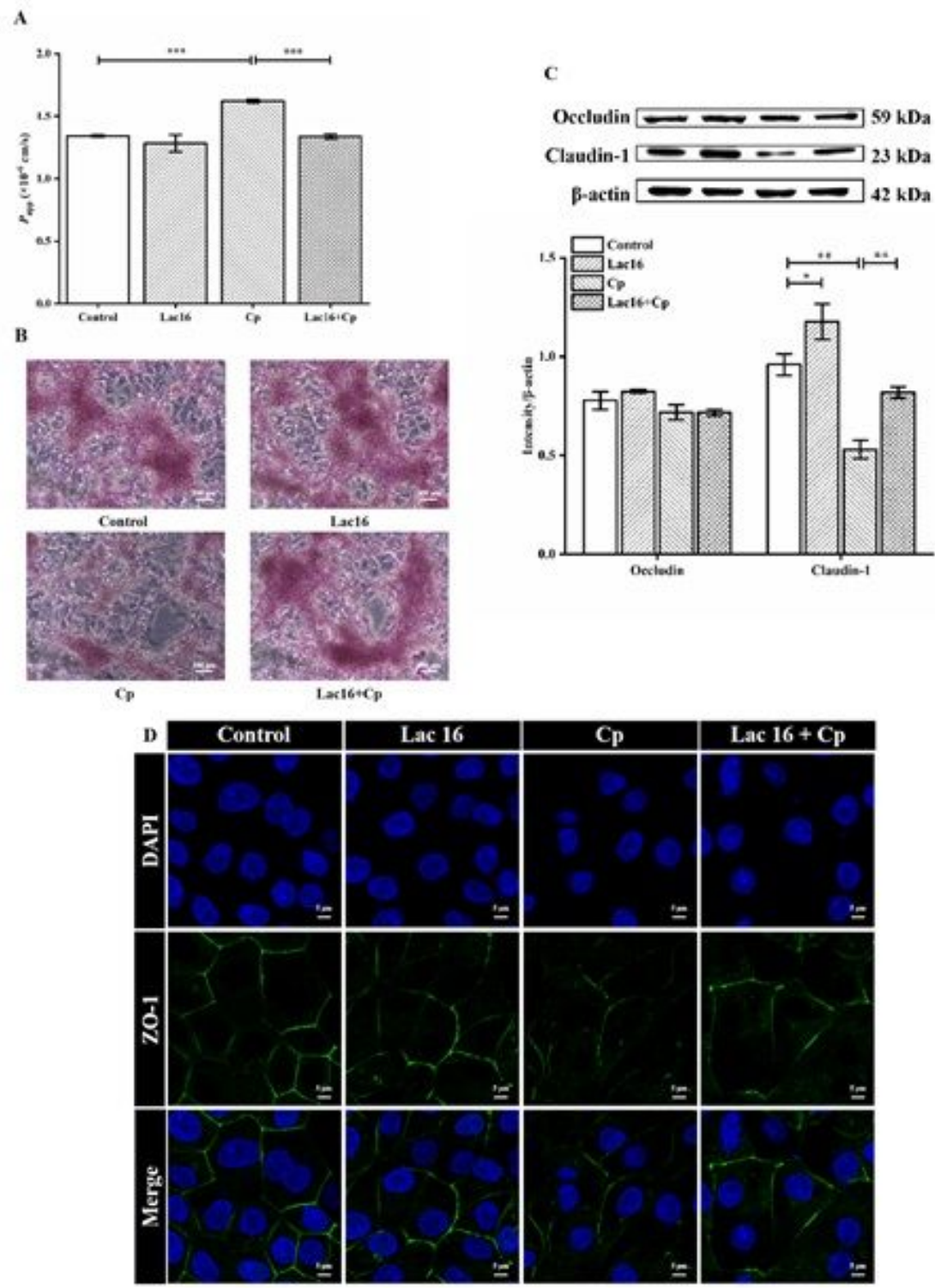

\section{Figure 4}

Intestinal barrier functions and tight junction proteins of IPEC-J2 cell monolayers. (A) Papp of IPEC-J2 monolayers based on apical-to-basolateral flux of fluorescein sodium. (B) Mucin production were detected by PAS staining. (C) Western blot detection of occludin and claudin-1 in IPEC-J2 cells. $\beta$-actin was used as an indicator of protein loading. (D) Immunofluorescence staining of ZO-1 (green) in IPEC-J2 cells. Nuclei were counterstained using DAPI (blue). All images were obtained at $63 \times$ magnification in oil. Data are presented as the means $\pm S D$ for $n=3$; * $P<0.05$, ** $P<0.01$ ( $t$ test). 

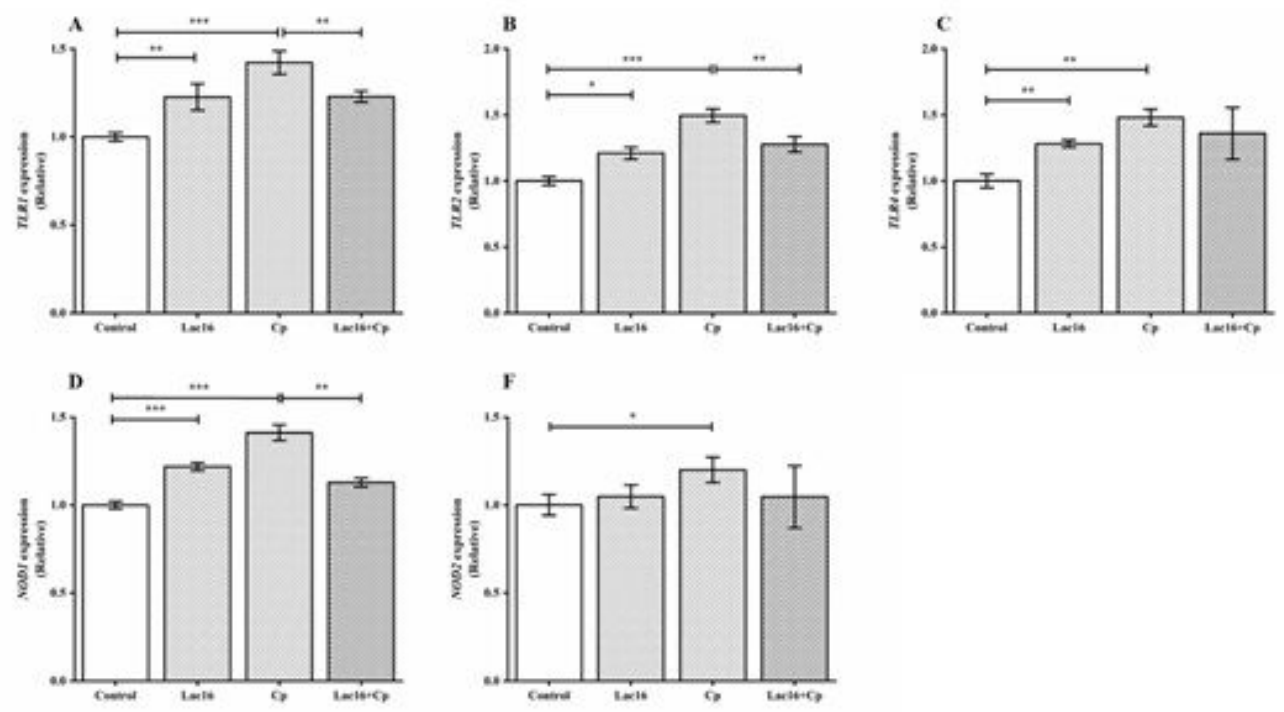

\section{Figure 5}

Relative gene expression levels of PRRs during C. Perfringens infection in IPEC-J2 cells preincubated with L. plantarum Lac16. (A) TLR1, (B) TLR2, (C) TLR4, (D) NOD1, (E) NOD2. mRNA expression was standardized to $\beta$ actin expression. Data are presented as the means $\pm S D$ for $n=3$; ${ }^{\star} P<0.05$, $* \star P<0.01$, $* \star * P<0.001$ ( $t$ test).
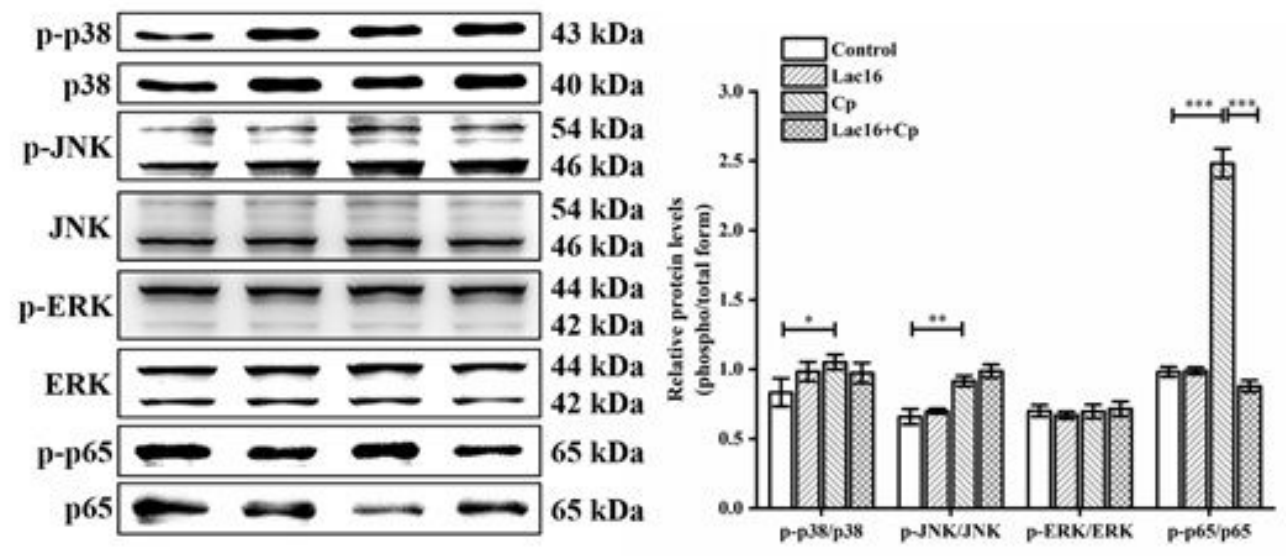

Figure 6

Western blot detection of MAPK and NF-KB pathways in IPEC-J2 cells. Quantitative analysis of the expression levels of phospho-p38/p38, phospho-JNK/JNK, phospho-ERK/ERK, and phosphor-p65/p65. Data are presented as the means $\pm S D$ for $\mathrm{n}=3$; ${ }^{\star} \mathrm{P}<0.05$, ${ }^{\star \star} \mathrm{P}<0.01$, ${ }^{\star \star \star} \mathrm{P}<0.001$ ( $\mathrm{t}$ test). 

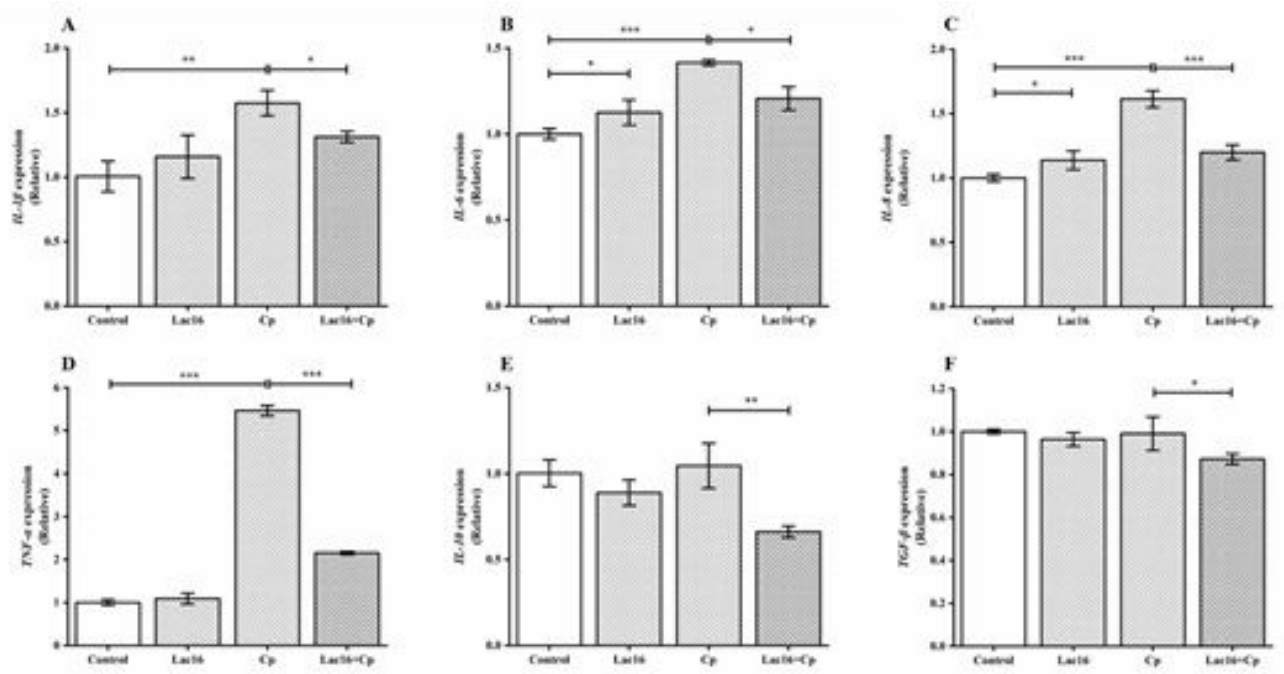

\section{Figure 7}

Relative gene expression levels of inflammatory cytokines during C. Perfringens infection in IPEC-J2 cells preincubated with L. plantarum Lac16. (A) IL-1 $\beta$, (B) IL-6, (C) IL-8, (D)TNF-a, (E) IL-10, (F) TGF- $\beta$. mRNA expression was standardized to $\beta$-actin expression. Data are presented as the means $\pm S D$ for $n=3$; * $P<0.05$,

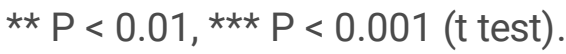

